\title{
In vivo intratumoral Epstein-Barr virus replication is associated with XBP1 activation and early-onset post-transplant lymphoproliferative disorders with prognostic implications
}

Blanca Gonzalez-Farre ${ }^{1,8}$, Jordina Rovira ${ }^{2,8}$, Daniel Martinez ${ }^{1}$, Alexandra Valera ${ }^{1}$, Adriana Garcia-Herrera ${ }^{1}$, Maria Angeles Marcos ${ }^{3}$, Carla Sole ${ }^{4}$, Gael Roue ${ }^{4}$, Dolors Colomer $^{1,4}$, Elena Gonzalvo ${ }^{1}$, Imma Ribera-Cortada ${ }^{1,5}$, Monica Araya ${ }^{6}$, Josep Lloreta ${ }^{7}$, Luis Colomo ${ }^{1}$, Elias Campo ${ }^{1}$, Armando Lopez-Guillermo ${ }^{2,9}$ and Antonio Martinez ${ }^{1,9}$

${ }^{1}$ Department of Pathology, Hospital Clínic, Institut d'Investigacions Biomèdiques August Pi i Sunyer (IDIBAPS), University of Barcelona, Barcelona, Spain; ${ }^{2}$ Hematology Unit, Hospital Clínic, University of Barcelona, Barcelona, Spain; ${ }^{3}$ Department of Microbiology, Barcelona Centre for International Health Research (CRESIB), Hospital Clinic, University of Barcelona, Barcelona, Spain; ${ }^{4}$ Experimental Therapy in Lymphpoid Malignancies Group, Institut d'Investigacions Biomediques Agusti Pi i Sunyer (IDIBAPS), University of Barcelona, Centre Esther Koplowitz, Barcelona, Spain; ${ }^{5}$ Department of Pathology, Hospital Nostra Senyora de Meritxell, Escaldes-Engordany, Principat d'Andorra, Spain; ${ }^{6}$ Department of Pathology, Hospital San Juan de Dios, San José, Costa Rica and ${ }^{7}$ Department of Pathology, Hospital del Mar, Institut Municipal d'Investigacions Mèdiques (IMIM), Autonomous University of Barcelona, Barcelona, Spain

Post-transplant lymphoproliferative disorders are life-threatening complications following hematopoietic or solid organ transplantation. They represent a spectrum of mostly EBV-driven lymphoplasmacytic proliferations. While the oncogenic effect of EBV is related to latent infection, lytic infection also has a role in lymphomagenesis. In vitro, EBV replication is linked to plasma cell differentiation and XBP1 activation, although this phenomenon has never been addressed in vivo. We analyzed for the first time latent and lytic intratumoral EBV infection in a series of 35 adult patients with a diagnosis of post-transplant lymphoproliferative disorder (26M/9F, median age 54 years). A complete EBV study was performed including the analysis of the latent EBER, latent membrane protein-11, and EBV nuclear antigens as well as the immediate-early BZLF1/ ZEBRA and early BMRF1/EADE31 lytic genes. XBP1 activation was assessed by nuclear protein expression. EBV infection was observed in $28(80 \%)$ cases being latency II and III the most frequently observed $22(79 \%)$. Intratumoral EBV replication was detected in $17(60 \%)$ cases. Among these, XBP1 activation was observed in $11 / 12$ evaluable cases associated with strong cytoplasmic immunoglobulin expression consistent with plasma cell differentiation. Intriguingly, the combination of latency III infection and EBV replication identified a high-risk subgroup of patients with significantly shorter survival (overall survival at 1 year $18 \%$ vs $48 \%$ ) and early-onset (median of 7 vs 26 months) post-transplant lymphoproliferative disorder. Moreover, these patients appear to be more heavily immunosuppressed, so they exhibit lower rates of rejection and graft vs host disease but higher rates of cytomegalovirus reactivation. In conclusion, EBV replication is associated with plasma cell

Correspondence: Dr A Martinez, MD, PhD, Department of Pathology, Hospital Clínic, Institut d’Investigacions Biomèdiques August Pi i Sunyer (IDIBAPS), University of Barcelona, Villarroel 170, E3/5P, 08036 Barcelona, Spain.

E-mail: antonmar@clinic.ub.es

${ }^{8}$ These authors contributed equally to this work.

${ }^{9} \mathrm{AM}$ and AL-G are the senior authors of the manuscript.

Received 12 December 2013; accepted 25 February 2014; published online 25 April 2014 
differentiation and XBP1 activation with prognostic implications. Both latency III and lytic EBV infection are related to aggressive and early-onset post-transplant lymphoproliferative disorder. These results suggest that immunohistochemical study of latent and lytic EBV genes in the clinical practice may help to select higher-risk patients to new therapies including antiviral treatments.

Modern Pathology (2014) 27, 1599-1611; doi:10.1038/modpathol.2014.68; published online 25 April 2014

Keywords: EBV; lymphoproliferative; plasma cell differentiation; post-transplant; replication; xbp1

Post-transplant lymphoproliferative disorders are lymphoid or plasmacytic proliferations that arise in the setting of immunosuppression following hematopoietic stem cell or solid organ transplantation. ${ }^{1,2}$ They represent a clinical and histopathological spectrum of disorders ranging from lesions with an excellent prognosis by reducing immunosuppressive treatments, to an overt aggressive lymphoma that requires immunochemotherapy. ${ }^{3}$ Although the incidence of post-transplant lymphoproliferative disorders is rising, probably due to the increasing number of transplant recipients and the longer survival of patients, the studies on series are short and heterogeneous. At present, no reliable morphologic, phenotypic, or genotypic marker has been identified to predict the outcome of patients in terms of response or survival. ${ }^{4}$

EBV infection is associated with more than $80 \%$ of B cell post-transplant lymphoproliferative disorders. $^{5-8}$ Nevertheless, the assessment of the EBV infection latency program is not consistently done throughout and even EBV status is unknown in up to $30 \%$ of the patients in some recently published series. ${ }^{9,10}$ EBV infection drives blastic transformation and uncontrolled proliferation in B cells mediated by constitutive expression of a limited set of latent viral genes, which are all oncogenic. ${ }^{3,5}$ In immunodeficient patients, all latent genes are expressed in a full growth-transforming program often found in these lymphomas, also known as latency III. ${ }^{7,11-13}$

Besides a latent stage, EBV infection has a lytic or replicative phase, which is characteristic of infectious mononucleosis and hairy oral leukoplakia. Very recently, a role for EBV replication in lymphomagenesis has also been proposed. ${ }^{3,14}$ Following infection with a lytic replication-defective EBV strain, humanized mice developed fewer post-transplant lymphoproliferative disorder-like lymphomas than wild-type EBV-infected mice, ${ }^{14}$ highlighting the importance of lytic phase in the development of the disease.

Immediate-early BZLF1/ZEBRA lytic gene expression is induced in vitro, following plasma cell differentiation and activation of the plasma cellassociated transcription factor XBP1. ${ }^{15,16}$ Nuclear XBP1 expression is a reliable marker of XBP1 activation and has been associated with poor prognosis in aggressive B-cell lymphomas, ${ }^{17}$ although its role in post-transplant lymphoproliferative disorders has never been addressed before.
Immediate-early BZLF1/ZEBRA and early BMRF1/ EADE31 viral genes initiate the lytic phase and their expression in EBV-infected tumor cells has been used to detect EBV replication in mice and human lymphomas. ${ }^{14,18}$

Both the growth-transforming and the replication programs are highly immunogenic stages of EBV infection that may be only tolerated in deeply immunosuppressed individuals. A systematic study of these different EBV latent and lytic programs in tumor cells has not been performed yet in patients with post-transplant lymphomas.

Reduction of immunosuppressive treatment and antiviral replication therapies are used in the clinical management of patients with post-transplant lymphoproliferative disorders. ${ }^{4,9,18-20}$ However, the decision to treat and the type of therapy a patient receives largely rely only on clinical features such as: current dosing, type of allograft, history of rejection, or infections. Thus, the effect of antiviral therapies is very controversial probably due to not considering the amount of intratumoral viral load and the EBV replication stage in the decision to treat a patient. ${ }^{18}$

In this study, we analyzed for the first time the role of both latent and lytic intratumoral EBV infection programs in a series of primary samples of post-transplant lymphoproliferative disorders, as well as the importance of plasma cell differentiation through the study of XBP1 in this group of patients.

\section{Materials and methods}

\section{Patients and Samples}

Thirty-five adult patients (26 males/9 females; median age of 54 years) diagnosed with posttransplant lymphoproliferative disorders at Hospital Clinic between 2000 and 2011 with available tissue biopsies were the subject of this study. Main clinical information was collected including type of transplant, time to lymphoma development, site of involvement, treatment, response, and follow-up. Main clinicobiological characteristics of the 35 patients are summarized in Table 1.

Cases were reviewed by three pathologists (AM, EC, BG-F) and classified according to the 2008 WHO classification. ${ }^{1}$

The study was performed according to the guidelines of the Ethic committee of Hospital Clínic de Barcelona. 
Table 1 Main clinicobiological characteristics of 35 patients with PTLD

\begin{tabular}{|c|c|}
\hline $\begin{array}{l}\text { Age, years (median, range) } \\
\text { Gender (male/female) }\end{array}$ & $\begin{array}{c}54(26-77) \\
26 / 9\end{array}$ \\
\hline $\begin{array}{l}\text { Transplanted organ } \\
\text { HSCT } \\
\text { Solid organ transplantation } \\
\text { Kidney } \\
\text { Liver } \\
\text { Heart }\end{array}$ & $\begin{aligned} 12 & (34 \%) \\
23 & (66 \%) \\
11 & (31 \%) \\
7 & (20 \%) \\
5 & (15 \%)\end{aligned}$ \\
\hline $\begin{array}{l}\text { Immunosuppressant therapy } \\
\text { Cyclosporine } \\
\text { Mycophenolate mophetil }\end{array}$ & $\begin{array}{l}24(75 \%) \\
16(50 \%)\end{array}$ \\
\hline $\begin{array}{l}\text { Receptor EBV-positive serology } \\
\text { Organ rejection/GVHD } \\
\text { CMV reactivation }\end{array}$ & $\begin{array}{l}27(93 \%) \\
21(65 \%) \\
12(39 \%)\end{array}$ \\
\hline $\begin{array}{l}\text { Time transplant to PTLD } \\
\quad<1 \text { year (early-onset PTLD) } \\
\text { >1 year (late-onset PTLD) }\end{array}$ & $\begin{array}{l}12(34 \%) \\
23(66 \%)\end{array}$ \\
\hline $\begin{array}{l}\text { Histological subtype } \\
\text { Polymorphic PTLD } \\
\text { Monomorphic PTLD } \\
\text { DLBCL } \\
\text { Plasmacytoma-like PTLD } \\
\text { Hodgkin lymphoma-type PTLD }\end{array}$ & $\begin{array}{r}6(17 \%) \\
26(74 \%) \\
1(3 \%) \\
2(6 \%)\end{array}$ \\
\hline $\begin{array}{l}\text { ECOG at lymphoma diagnosis } \\
\quad 0 \\
1 \\
2 \\
3-5\end{array}$ & $\begin{array}{r}19(59 \%) \\
9(28 \%) \\
4(13 \%) \\
0\end{array}$ \\
\hline B symptoms & $19(60 \%)$ \\
\hline $\begin{array}{l}\text { Ann Arbor Stage } \\
\text { I } \\
\text { II } \\
\text { III } \\
\text { IV }\end{array}$ & $\begin{array}{r}10(31 \%) \\
9(28 \%) \\
0 \\
13(41 \%)\end{array}$ \\
\hline $\begin{array}{l}\text { Transplanted organ dysfunction } \\
\text { Transplanted organ involvement } \\
\text { CNS involvement } \\
\text { High serum LDH } \\
\text { High serum } \beta 2 \mathrm{~m}\end{array}$ & $\begin{array}{r}10(31 \%) \\
6(17 \%) \\
7(22 \%) \\
23(72 \%) \\
19(95 \%)\end{array}$ \\
\hline
\end{tabular}

Abbreviations: CNS, central nervous system; DLBCL, diffuse large B-cell lymphoma; EBV, Epstein-Barr virus; HSCT, hematopoietic stem cell transplantation; PTLD, post-transplant lymphoproliferative disorder.

\section{Epstein-Barr Virus and Immunophenotypic Studies}

Epstein-Barr virus (EBV) was detected using in situ hybridization with EBER probes (INFORM EBER, Roche Diagnostics, Basel, Switzerland). Immunohistochemical studies were also performed for the detection of latency proteins: latent membrane protein-1 (LMP-1) (clone CS1-CS5, Dako, Glostrup, Denmark), EBV nuclear antigen-2 (EBNA-2) (clone EP2, Leica Biosystems, Newcastle, United Kingdom) and lytic genes: BZLF1/ZEBRA (Argene, AZ-69, Varilhes, France) and BMRF1/EADE31(clone G3E31, Leica Biosystems, Newcastle, United Kingdom) as described elsewhere. ${ }^{21}$ The activation of the plasma cell-related transcription factor XBP1s
(Xbp-1-M186, Santa Cruz Biotechnology, Santa Cruz, CA) was analyzed as previously described. ${ }^{17}$ A cutoff of $30 \%$ of nuclear positivity was used to be considered positive.

EBV DNA was isolated from plasma, cerebrospinal fluid or tissue with QIAsymphony Virus/Bacteria Midi kit (Qiagen, Hilden, Germany). EBV quantification was performed with EBV Q-PCR Alert AmpliMIX (Nanogen Advanced Diagnostics, Torino, Italy) and ABI PRISM 7300 platform (PE Applied Biosystems, Foster City, CA). The limit of detection is 10 copies/reaction.

\section{Western Blot}

Frozen tumor samples were lysed in a non-denaturing detergent (M-PER and T-PER, Pierce, Rockford, IL) containing protease inhibitors (Complete Mini, Roche) and phosphatase inhibitors (Cocktails 1 and 2, Sigma, Saint Louis, MO) as previously described. ${ }^{17}$ Nitrocellulose membranes were incubated with mouse anti BZLF1 (LsBio) and mouse anti- $\alpha$-actin (Sigma, St Louis, MO) as a loading control. Binding was detected using an enhanced Chemoluminescent Supersignal-FEMTO (Pierce). Visualization and image analysis were performed in a mini LAS-4000 camera system (Fuji Photo Film, Minato-Ku, Tokyo, Japan). Protein quantification was done with Image Gauge Software (Fujifilm, Düsseldorf, Germany).

\section{Fluorescence 'In Situ' Hybridization}

MYC (8q24), BCL-2 (18q21), and BCL-6 (3q26) gene status was studied by fluorescence 'in situ' hybridization (FISH) performed on $3-4-\mu \mathrm{m}$ thick sections of formalin-fixed paraffin-embedded tissues, using dual color-break apart probes (Abbott Molecular, Illinois) as described. ${ }^{22}$

\section{IgH Gene Rearrangements}

DNA for the study of $I G H V$ gene rearrangements was extracted from tissue sections using the QIAamp DNA mini kit (Qiagen). Purified DNA was amplified using primers of the Framework Regions 1 and 3 (FR-1 and FR-3) and JH alpha regions of the immunoglobulin heavy chain gene (IgH-PCR), using the BIOMED2 protocol. ${ }^{23}$

\section{Assessment of Response and Outcome}

Complete response was defined as the total disappearance of tumor masses and any other detectable clinical evidence of disease and disease-related symptoms for at least 1 month. Partial response was considered when tumor mass or organ infiltration decreased by at least $50 \%$ along with the disappearance of disease-related symptoms. Patients not 
included in these categories and early deaths were considered as non-responders. Disease relapse or progression was defined as the appearance of new symptoms or signs of the disease as demonstrated by lymph node biopsy or other appropriate studies. ${ }^{24}$ To consider solid organ rejection or graft vs host disease, along with clinical suspicion, histologic evidence of organ injury was needed. Cytomegalovirus reactivation was considered when any viral load is detected in peripheral blood during posttransplant period.

\section{Statistical Methods}

Differences among the subgroups of patients were assessed by using the $\lambda^{2}$ test (two-tailed), the Student's $t$-test or non-parametric tests when necessary. The actuarial survival analysis was performed by the Kaplan-Meier method and log-rank test. Overall survival was calculated according to standard definitions. ${ }^{24}$

\section{Results}

EBV Latent Infection in Post-Transplant Lymphoproliferative Disorders: Histological, Molecular, and Genetics Subtypes

After review, 26 cases (74\%) were classified as diffuse large B-cell lymphoma, 6 cases (17\%) as polymorphic post-transplant lymphoproliferative disorders, 2 cases $(6 \%)$ as classical Hodgkin lymphoma, and $1(3 \%)$ as plasmacytoma-like lesion. None of the early lesions, neither infectious mononucleosis nor plasma cell hyperplasia, were identified probably due to the fact that those lesions are more frequently found in children, and our series lack pediatric cases with a median age of 54 years old.

EBV infection in tumor cells was observed in 28 patients $(80 \%)$ assessed by strong nuclear expression of small EBV-encoded RNA genes, EBER 1 and 2. According to LMP-1 and EBNA-2 gene expression, the most common latency pattern was latency III observed in 13 patients (46\%) followed by latency II in $9(32 \%)$, and latency I in $6(21 \%)$ (Figure 1).

All the polymorphic cases were EBV positive and $67 \%$ exhibit a latency III pattern of infection. In cases diagnosed as diffuse large B-cell lymphoma, EBV-infected tumor cells were observed in 19/26 cases $(73 \%)$ with a latency III pattern in $47 \%$. As expected, the two Hodgkin lymphoma cases were also EBV positive with a latency II. The plasmacy- toma-like lesion was also EBV positive with a latency I pattern.

Clonality studies were available in 14 patients. Among diffuse large B-cell lymphoma cases, 7/10 showed a monoclonal IgH rearrangement and three of them were EBV positive, with latency III in $67 \%$. Conversely, two of the four polymorphic cases studied were monoclonal and both were EBV positive with latency I and III, respectively.

Cytogenetic studies of $M Y C, B C L-2$, and $B C L-6$ were done in all cases. Genetic alterations were found in six cases, five of them EBV negative. $M Y C$ gains were observed in four EBV-negative diffusely large B-cell lymphomas and one EBV-positive polymorphic post-transplant lymphoproliferative disorder with latency I. This case was the only one with additional genetic alterations such as gains of $B C L-6$ and $B C L-2$. An MYC rearrangement was observed only in one EBV-negative diffusely large B-cell lymphoma.

Only 13 cases, 12 following hematopoietic stem cell transplant and one following kidney transplant, were analyzed for donor vs host origin of tumor cells. All of them were of donor origin and all were also EBV +. Main cytogenetic features are listed in Table 2.

\section{EBV Replication is Associated with Latency III and Monoclonal Diffusely Large B-cell Lymphoma}

EBV replication was assessed by nuclear expression of the immediate-early BZLF1 and early BMRF1 lytic genes. A case was considered positive when more than two positive cells were seen in whole tumor section (Figure 2a). Although replication was mostly observed in large atypical tumor cells, scattered EBV replication-positive small lymphocytes were observed in three cases. EBV replication was detected in $17 / 28$ tumors $(60 \%)$ mainly with expression of both lytic genes. Only one case was negative for BZLF1 but positive for BMRF1.This case was considered to harbor intratumoral EBV replication. Western blot for BZLF1 was performed in five cases from available frozen material, three of them highly replicative and two with few positive cells by immunohistochemistry. The results of the western blot study are shown in Figure $2 b$.

According to intratumoral EBV replication, three groups were considered: the first one formed by patients who had EBV infection associated with EBV replication $(\mathrm{EBV}+/ \mathrm{R}+)(n=17,49 \%)$; the second, included patients with EBV infection without EBV replication $(\mathrm{EBV}+/ \mathrm{R}-)(n=11,31 \%)$; and the last

Figure 1 Left panel displays a diffuse large B-cell lymphoma with latency III Epstein-Barr virus (EBV) infection pattern. (a) Tumor is composed of large atypical cells with immunoblastic features and admixed plasma cells H\&E $(\times 20)$. The atypical cells express intense (b) CD20 ( $\times 20)$, and are infected by EBV $(\mathbf{c})$ EBER $(\times 10)$, with expression of $(\mathbf{d})$ LMP-1 $(\times 20)$ and $(\mathbf{e})$ EBNA-2 $(\times 20)$. Right panel shows a polymorphic post-transplant lymphoma with (f) prominent plasmacytic differentiation H\&E $(\times 20)$ with low (g) CD20 expression and a latency II EBV infection pattern with expression of $(\mathbf{h})$ EBER $(\times 40)$, (i) LMP-1 $(\times 40)$ but $(\mathbf{j})$ negativity for EBNA-2 $(\times 20)$. 

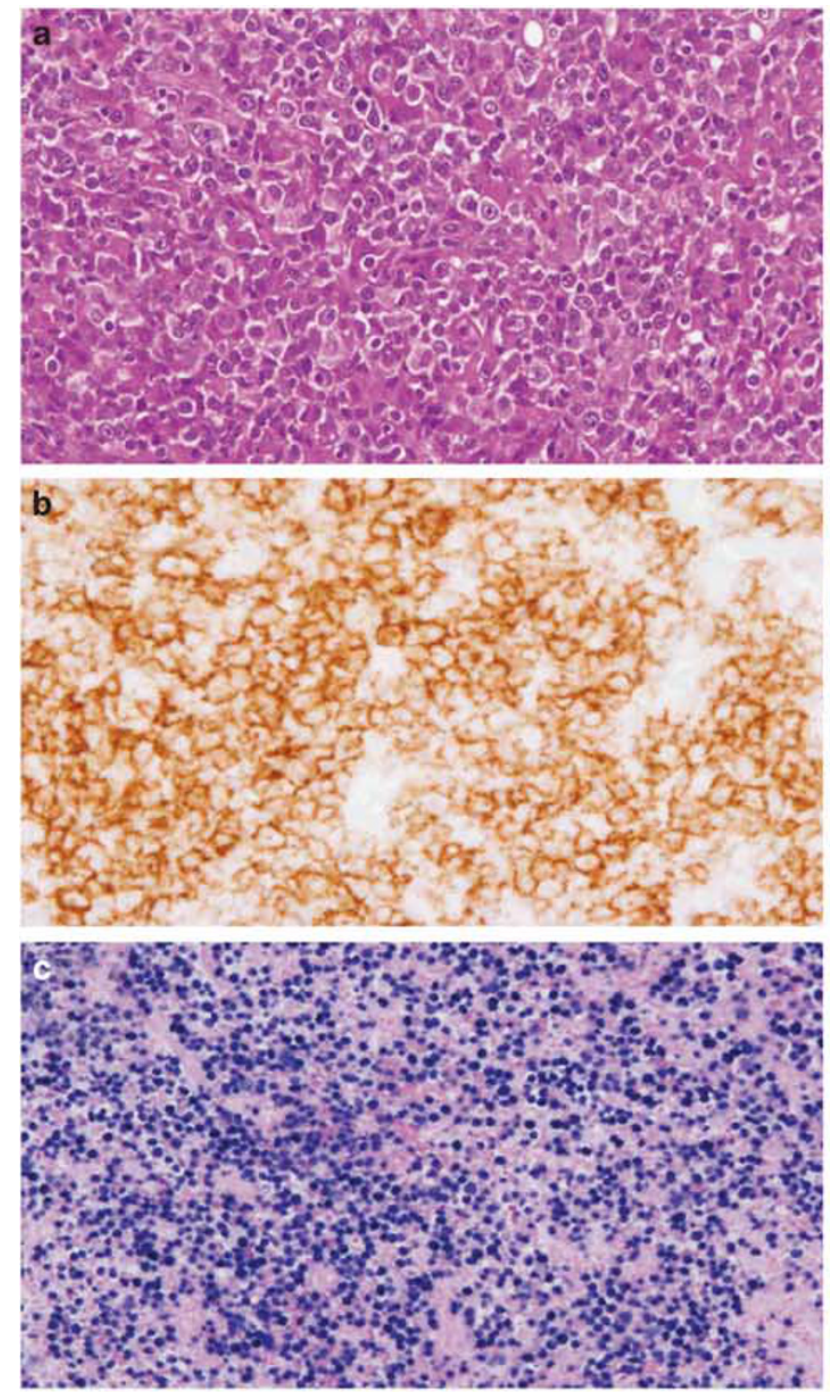

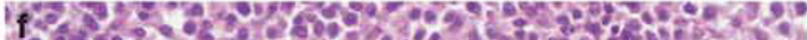

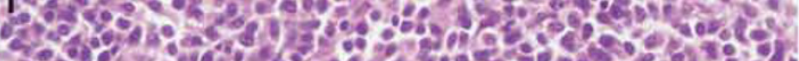

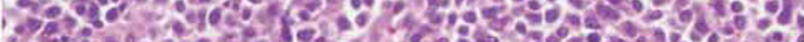

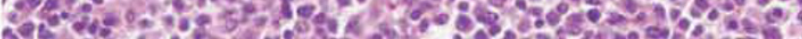

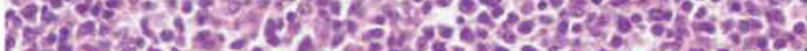

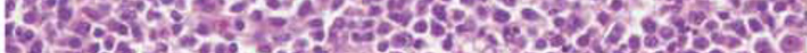

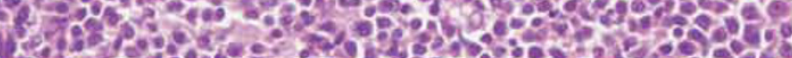

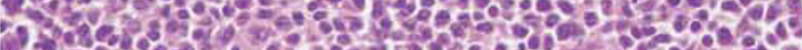

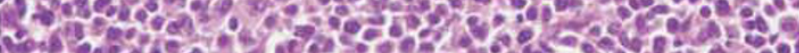

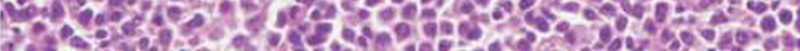

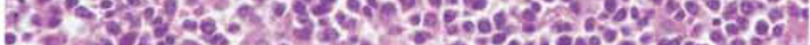

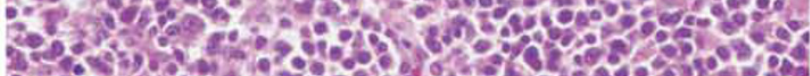
900 -

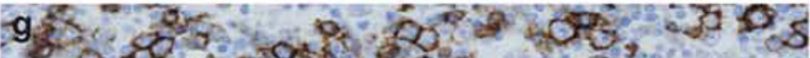

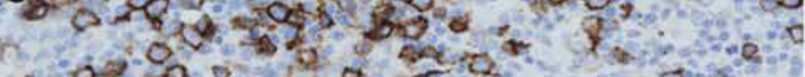

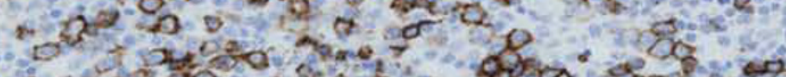

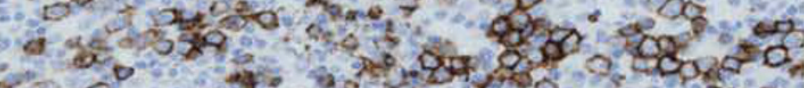

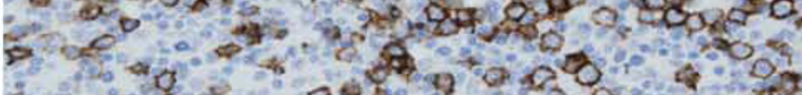

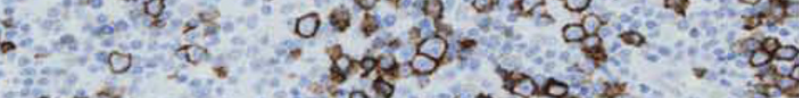

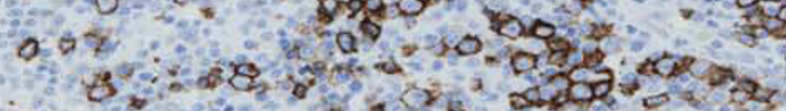

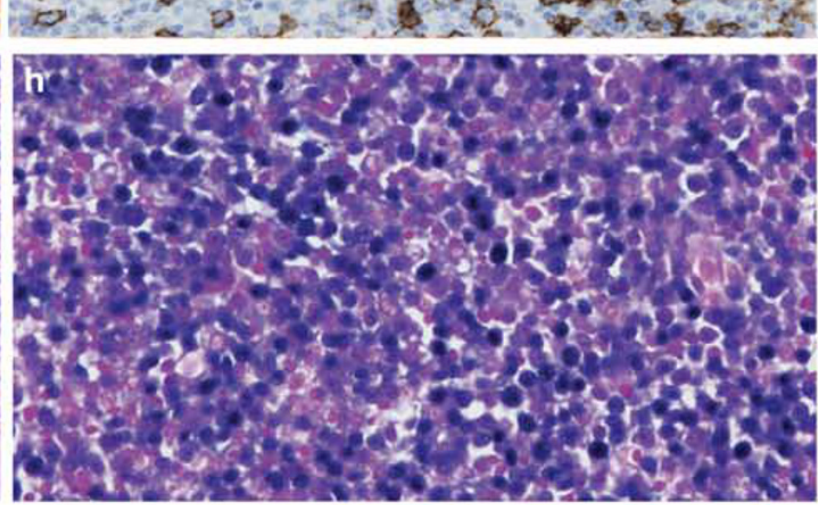

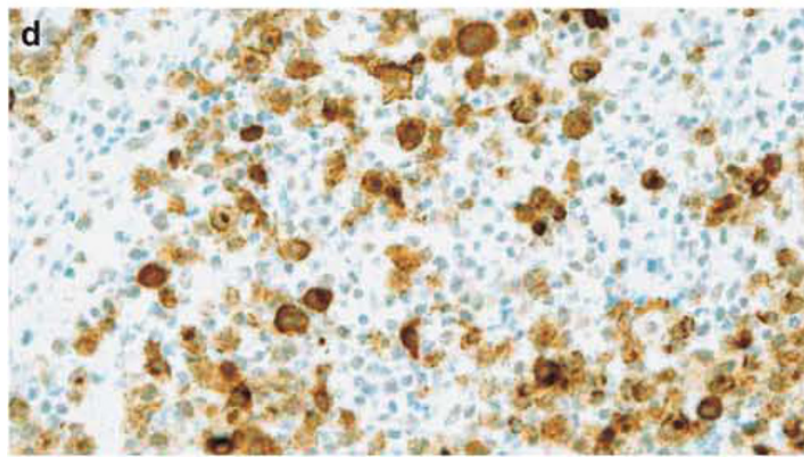
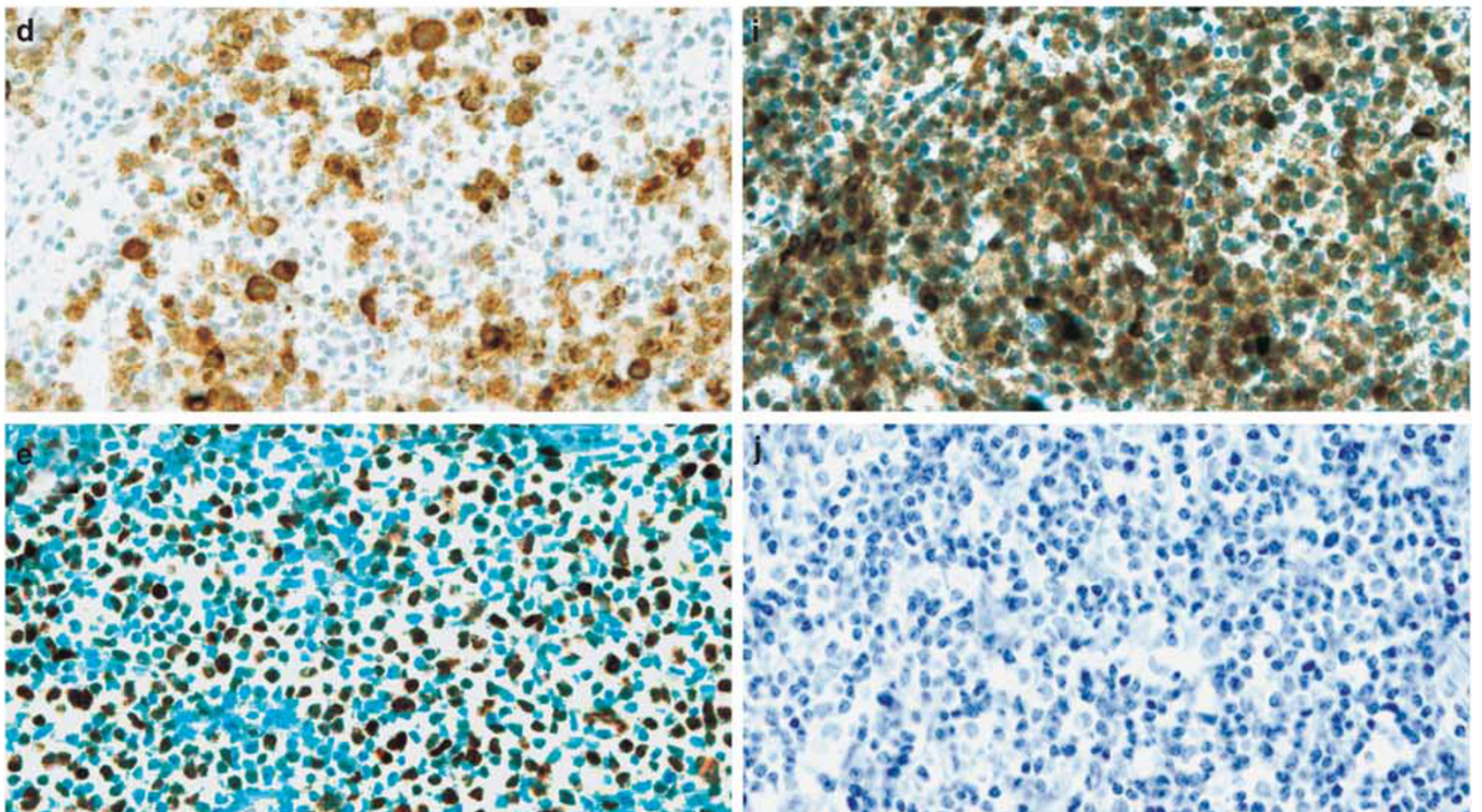
Table 2 Molecular and genetic features of 35 PTLD cases

Genetics

\begin{tabular}{|c|c|c|c|c|c|c|c|}
\hline Case & Diagnosis & Type of transplant & Host vs donor origin & Clonality & CMYC & $B C L-2$ & $B C L-6$ \\
\hline 1 & DLBCL & HSCT & Donor & ND & Normal & Normal & Normal \\
\hline 2 & DLBCL & HSCT & Donor & ND & Normal & Normal & Normal \\
\hline 3 & DLBCL & HSCT & Donor & Polyclonal & Normal & Normal & Normal \\
\hline 4 & DLBCL & HSCT & Donor & ND & Normal & Normal & Normal \\
\hline 5 & DLBCL & HSCT & Donor & ND & Normal & Normal & Normal \\
\hline 6 & Polymorphic PTLD & HSCT & Donor & Clonal & Normal & Normal & Normal \\
\hline 7 & Polymorphic PTLD & HSCT & Donor & Clonal & Gains & Gains & Gains \\
\hline 8 & Polymorphic PTLD & HSCT & Donor & ND & $\mathrm{NE}$ & Normal & Normal \\
\hline 9 & Polymorphic PTLD & HSCT & Donor & ND & Normal & Normal & Normal \\
\hline 10 & Polymorphic PTLD & HSCT & Donor & Polyclonal & $\mathrm{NE}$ & $\mathrm{NE}$ & Normal \\
\hline 11 & Hodgkin lymphoma & HSCT & Donor & ND & $\mathrm{NE}$ & $\mathrm{NE}$ & $\mathrm{NE}$ \\
\hline 12 & Hodgkin lymphoma & HSCT & Donor & ND & NE & $\mathrm{NE}$ & NE \\
\hline 13 & DLBCL & Liver & ND & Clonal & NE & $\mathrm{NE}$ & $\mathrm{NE}$ \\
\hline 14 & DLBCL & Liver & ND & ND & Normal & Normal & Normal \\
\hline 15 & DLBCL & Liver & ND & ND & $\mathrm{NE}$ & $\mathrm{NE}$ & $\mathrm{NE}$ \\
\hline 16 & DLBCL & Liver & ND & Polyclonal & $\mathrm{NE}$ & $\mathrm{NE}$ & $\mathrm{NE}$ \\
\hline 17 & DLBCL & Liver & ND & ND & Normal & Normal & Normal \\
\hline 18 & DLBCL & Liver & ND & ND & Gain & $\mathrm{NE}$ & $\mathrm{NE}$ \\
\hline 19 & Polymorphic PTLD & Liver & ND & Polyclonal & Normal & Normal & Normal \\
\hline 20 & DLBCL & Kidney & ND & Clonal & Normal & Normal & Normal \\
\hline 21 & DLBCL & Kidney & ND & Clonal & Normal & Normal & Normal \\
\hline 22 & DLBCL & Kidney & ND & ND & NE & NE & NE \\
\hline 23 & DLBCL & Kidney & ND & ND & Normal & Normal & Normal \\
\hline 24 & DLBCL & Kidney & Donor & Clonal & $\mathrm{NE}$ & $\mathrm{NE}$ & $\mathrm{NE}$ \\
\hline 25 & DLBCL & Kidney & ND & ND & NE & Normal & Normal \\
\hline 26 & DLBCL & Kidney & ND & Polyclonal & NE & $\mathrm{NE}$ & $\mathrm{NE}$ \\
\hline 27 & DLBCL & Kidney & ND & ND & ND & $\mathrm{NE}$ & $\mathrm{NE}$ \\
\hline 28 & DLBCL & Kidney & ND & ND & Gains & Gains & Normal \\
\hline 29 & DLBCL & Kidney & ND & ND & Gains & $\mathrm{NE}$ & $\mathrm{NE}$ \\
\hline 30 & DLBCL & Kidney & ND & ND & $\mathrm{NE}$ & $\mathrm{NE}$ & NE \\
\hline 31 & DLBCL & Heart & ND & Clonal & $\mathrm{NE}$ & $\mathrm{NE}$ & $\mathrm{NE}$ \\
\hline 32 & DLBCL & Heart & ND & Clonal & Rearranged & Normal & Normal \\
\hline 33 & DLBCL & Heart & ND & Clonal & Gains & Normal & Normal \\
\hline 34 & DLBCL & Heart & ND & ND & Normal & Normal & Normal \\
\hline 35 & Plasmacytoma-like lesion & Heart & ND & ND & $\mathrm{NE}$ & Normal & Normal \\
\hline
\end{tabular}

Abbreviations: DLBCL, diffuse large B-cell lymphoma; HSCT, hematopoietic stem cell transplantation; ND, not-done; NE, not evaluable; PTLD, Post-transplant lymphoproliferative disorder.

with EBV-negative patients (EBV - ) $(n=7,20 \%)$. Main clinicopathological features of these patients according to EBV replication status are listed in Table 3.

The EBV +/R + group encompasses 12 diffuse large B-cell lymphoma cases and five polymorphic ones. Neither the Hodgkin lymphoma cases nor the plasmacytoma were associated with intratumoral EBV replication. Latency III infection pattern was more frequently observed in patients with active replication $(11 / 17,65 \%$ vs $2 / 11,18 \%$ for $\mathrm{EBV}+/ \mathrm{R}+$ and $\mathrm{EBV}+/ \mathrm{R}-$ cases, respectively, $P=0.017)$. Interestingly, all 13 cases proved to be of donor origin were EBV positive, 8 with replication.

\section{EBV Replication is Related to XBP1 Activation and Plasma Cell Differentiation}

As plasma cell differentiation and EBV replication converges in XBP1 activation, we then analyzed
XBP1 expression by immunohistochemistry. Among diffuse large B-cell lymphoma cases, nuclear XBP1 expression was found in 9 of 32 cases studied. Positivity was observed quite homogeneously among tumor cells. In some cases, cytoplasmic expression was also seen. Strong nuclear expression was observed in plasma cells as well as in the small and large lymphocytes with variable degrees of plasma cell differentiation in all five polymorphic cases studied. None of the Hodgkin cases had nuclear XBP1 expression. All of them were EBV positive without intratumoral viral replication. Interestingly, the only case of plasmacytoma-like lesion was strongly positive for XBP1, probably related to a full secretory transformation of tumor cells. This case was EBV positive with latency I without intratumoral replication.

Remarkably, among EBV-positive cases, a strong correlation was found between viral replication and nuclear XBP1 expression $(11 / 12 \mathrm{R}+$ vs $4 / 11 \mathrm{R}-$; $P=0.005$ ) (Figure 2c). 


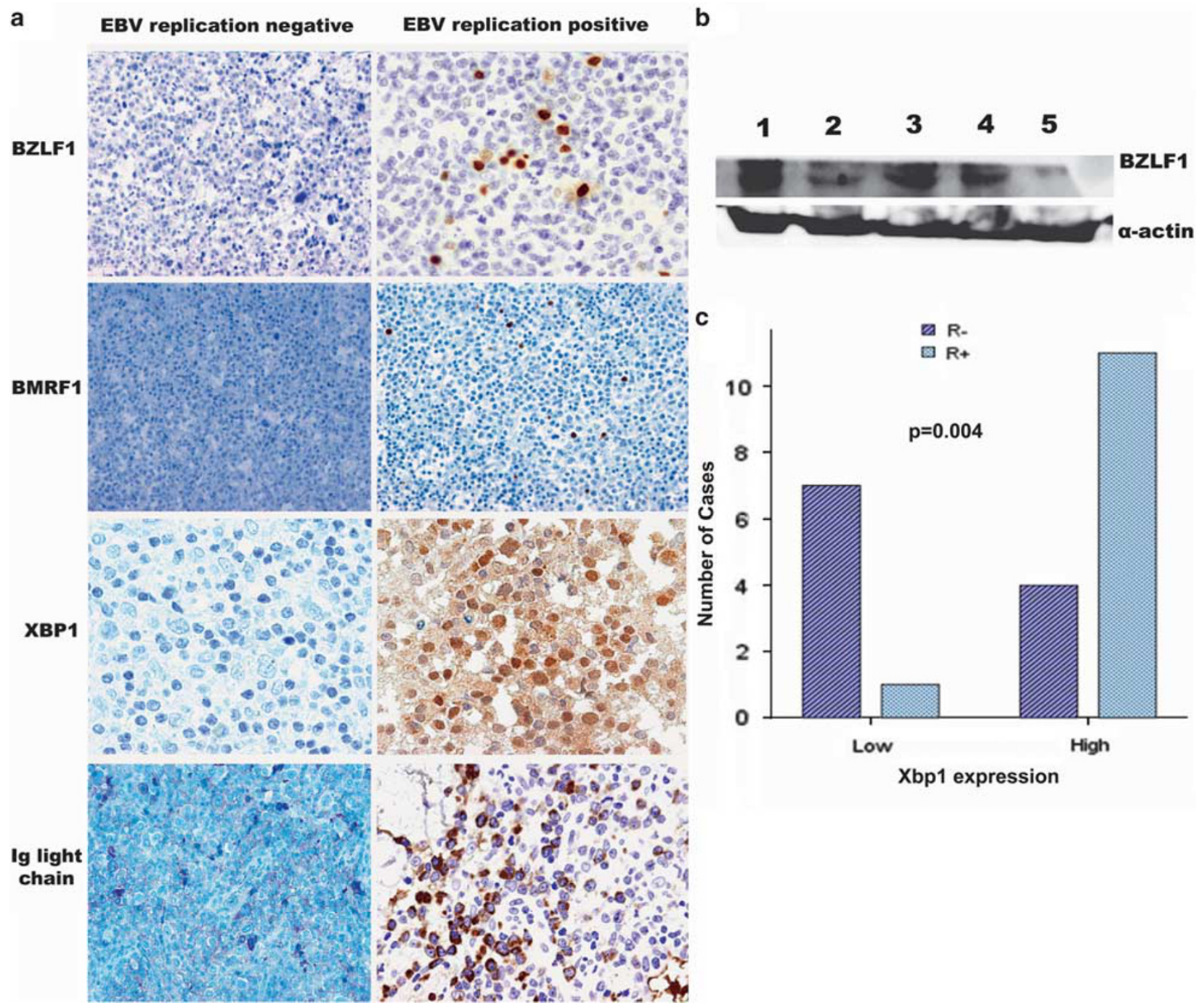

Figure 2 (a) Intratumoral Epstein-Barr virus (EBV) replication and XBP1 expression. Left panel shows a case of diffuse large B-cell lymphoma without EBV replication, negative for BZLF1 $(\times 20)$ and BMRF1 $(\times 20)$ and negativity for XBP1 $(\times 40)$ and without light chain expression. Right panel, depicts a polymorphic post-transplant lymphoma with high EBV replication, positive for BZLF1 $(\times 20)$ and BMRF1 $(\times 20)$ with high nuclear XBP1 expression $(\times 40)$ and strong cytoplasmic light chain expression. (b) Western Blot for BZLF1. Cases 1, 3, and 4 correspond to highly replicative tumors; cases 2 and 5 correspond to low replication samples. (c) EBV replication is significantly higher in XBP1-positive cases $(P=0.004)$.

\section{EBV Replication is Associated with Early Post-Transplant Lymphoproliferative Disorder}

Twenty-three patients (66\%) received solid organ transplantation, including kidney in 11 cases. Most patients $(97 \%)$ were receiving immunosuppressive therapy at the time of diagnosis. The median interval between transplant and the onset of the lymphoma was 26 months (range 2-252 months). The lapsed time between transplant and the diagnosis was 5 months in hematopoietic stem cell transplantation recipients and 61 months following solid organ transplantation $(P=0.0004)$. Twelve patients $(34 \%)$ were diagnosed with early-onset post-transplant lymphoproliferative disorder $(<1$ year after transplant) and 23 (66\%) with late onset. Earlyonset cases were more frequently observed in hematopoietic stem cell transplantation recipients (9/12 vs 3/23 for hematopoietic and solid organ, respectively; $P=0.0005$ ). No significant correlation was found between the time from transplant and EBV serology status, organ rejection or graft vs host disease presence. Reactivation of cytomegalovirus infection was observed in 12 patients (39\%), and it was more frequent in patients with an early than late post-transplant lymphomas $(7 / 12$ vs $4 / 20 ; P=0.04)$. Polymorphic cases showed more frequently an early-onset than the other histological subgroups (5/6 vs $7 / 29 ; P=0.0118$ ) whereas in the late-onset group, the most frequent subtype found were the 
Table 3 Main clinicobiological characteristics according to EBV status

\begin{tabular}{|c|c|c|c|}
\hline & $E B V-$ & $E B V+/ R-$ & $E B V+/ R+$ \\
\hline Age, years (median, range) & $58(41-77)$ & $50(30-74)$ & $56(26-75)$ \\
\hline Gender (male/female) & $4 / 3$ & $8 / 3$ & $14 / 3$ \\
\hline SOT/HSCT & $7 / 0$ & $8 / 3$ & $9 / 8$ \\
\hline Rejection or GVHD & $5 / 6(83 \%)$ & $7 / 10(70 \%)$ & $9 / 16(56 \%)$ \\
\hline CMV reactivation & $1 / 6(17 \%)$ & $2 / 10(20 \%)$ & $9 / 16(56 \%)$ \\
\hline \multicolumn{4}{|l|}{ Time transplant to PTLD* } \\
\hline Median, range (months) & $139(46-252)$ & $44(4-206)$ & $7(2-119)$ \\
\hline$<1$ year (early-onset PTLD) & 0 & $2(18 \%)$ & $10(59 \%)$ \\
\hline$>1$ year (late-onset PTLD) & $7(100 \%)$ & $9(81 \%)$ & $7(41 \%)$ \\
\hline \multicolumn{4}{|l|}{ Histological subtype } \\
\hline \multicolumn{4}{|l|}{ Monomorphic PTLD } \\
\hline DLBCL & 7 & 7 & 12 \\
\hline Plasmacytoma-like PTLD & 0 & 1 & 0 \\
\hline Polymorphic PTLD & $0^{*}$ & 1 & 5 \\
\hline Hodgkin lymphoma-type PTLD & 0 & 1 & 0 \\
\hline EBV latency pattern I/II/III* & & $5 / 4 / 2$ & $1 / 5 / 11$ \\
\hline Advanced stage at diagnosis & $2 / 7(26 \%)$ & $5 / 11(45 \%)$ & $7 / 17(41 \%)$ \\
\hline Complete response & $4 / 7(57 \%)$ & $4 / 10(40 \%)$ & $5 / 15(33 \%)$ \\
\hline OS (from PTLD) at 1 year (\%) & 57 & 45 & 25 \\
\hline
\end{tabular}

Abbreviations: CMV, cytomegalovirus; DLBCL, diffuse large B-cell lymphoma; EBV, Epstein-Barr virus; GVHD, graft vs host disease; HSCT, hematopoietic stem cell transplantation; OS, overall survival; PTLD, post-transplant lymphoproliferative disorder; R, viral replication; SOT, solid organ transplantation.

${ }^{*} P<0.05$.

monomorphic $(20 / 23$ vs $7 / 12 ; P=0.0331)$. Patients with $\mathrm{EBV}+/ \mathrm{R}+$ lymphomas had more frequently an early-onset of the disease $(10 / 17$ vs 2/18; $P=0.09)$. The median time from transplant was significantly shorter in this group of patients (7 months) than in EBV + $/ \mathrm{R}-$ (45 months) and EBV - (140 months) $(P<0.001)$.

According to the site of involvement, 9 cases were nodal and 26 were extranodal, including gastrointestinal tract $(n=5)$, liver $(n=4)$, and central nervous system (CNS) $(n=5)$. All cases with CNS involvement were EBV positive. The main features of the cases at diagnosis are detailed in Table 1. Thirteen patients (40\%) had disseminated disease, including bone marrow and CNS involvement in six and two patients, respectively.

EBV PCR was positive in peripheral blood in seven patients and in cerebrospinal fluid in six at the moment of the diagnosis. In $77 \%$ of these cases, intratumoral EBV replication was observed in the biopsy. In three cases, PCR was negative at the onset of an EBV-positive lymphoma. Two of them did not exhibit intratumoral EBV replication.

Curiously, cytomegalovirus reactivation was more frequently observed in the group of patients who developed a latency III EBV-positive lymphomas with intratumoral replication $(7 / 11$ vs $5 / 21$, $P=0.003)$. This group of patients tend to have a lower incidence of graft $v S$ host disease or solid organ rejection $(7 / 11$ vs $14 / 21, P=0.0582)$.

\section{Aggressive Post-Transplant Lymphoproliferative Disorders are Associated with the Combination of Latency III, Viral Replication, and XBP1 Activation}

The front-line treatment slightly varied over the time and often combined different modalities, but could be summarized as follows: decreased immunosuppressive therapy (90\%), rituximab (71\%), adriamycincontaining chemotherapy (45\%). Eleven patients were treated with others regimens, including radiotherapy, surgery, lymphocytes infusion, and intrathecal methotrexate. No difference was found according to the time of lymphoma onset. Three patients were not treated. Thirteen patients $(41 \%)$ achieved complete response and four (12\%) obtained a partial response whereas 15 patients (47\%) were considered non-responders including three early deaths. One of the 13 patients with complete response eventually relapsed at 14 months.

After a median follow-up for surviving patients of 74 months, 26 patients have died with a 1-year overall survival of $38 \%$ (95\% CI: 22-54.9). One year overall survivals between early and late-onset posttransplant cases were $37 \%$ and $39 \%$, respectively. The causes of death were disease progression $(n=19)$, infection $(n=3)$, organ rejection $(n=3)$, and second neoplasia $(n=1)$. Overall survival according EBV infection and replication are showing a 1-year overall survival of $25 \%, 45 \%$, and $57 \%$ for $\mathrm{EBV}+/ \mathrm{R}+, \mathrm{EBV}+/ \mathrm{R}-$, and $\mathrm{EBV}$ patients, respectively $(P=\mathrm{NS}$ ) (Figure 3$)$. Interestingly, the 

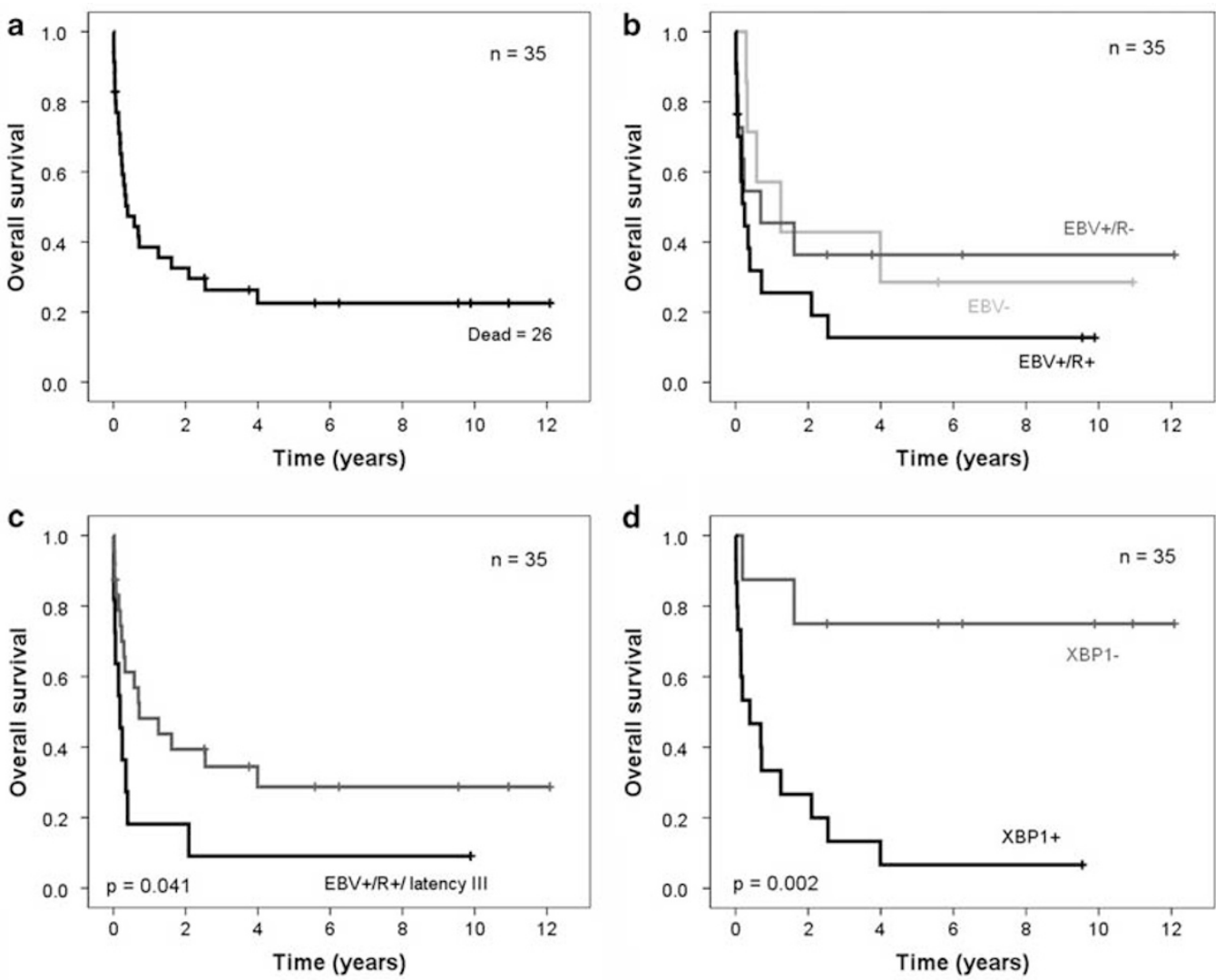

Figure 3 (a) Overall survival of all patients with post-transplant lymphoproliferative disorders. Overall survival according to (b) EBV replication, (c) coexpression of the highly immunogenic program latency III and active viral replication and (d) XBP1 activation.

group with latency III infection pattern and intratumoral EBV replication showed significant shorter survival ( $18 \%$ vs $48 \%, P=0.041$ ) (Figure 3 ).

Nuclear XBP1 expression was also associated with aggressive behavior with a 1-year overall survival of $33 \%$ for the XBP1-positive cases vs $87 \%$ for the negative ones $(P=0.002)$.

\section{Discussion}

We reported a series of post-transplant lymphoproliferative disorders with extensive EBV investigation which, for the first time, addresses the role of intratumoral viral replication in tissues. EBV has a major role in the development of post-transplant lymphomas, as infected tumor cells are present in the majority of cases. ${ }^{6}$ Primary EBV infection often precedes the onset of pediatric cases and EBV seronegativity at the time of transplantation is a major risk factor for the development of posttransplant lymphomas. ${ }^{25,26}$ Moreover, prophylactic antiviral therapies are effective in preventing posttransplant lymphomas, particularly in children, highlighting the role of primary EBV infection or EBV reactivation in their development. ${ }^{19,20,27}$

During primary EBV infection and EBV reactivation, active viral replication occurs. ${ }^{28}$ Viral replication is the hallmark of the lytic phase and EBV replication has an important role in lymphomagenesis. ${ }^{14,29}$ Humanized mice infected with lytically active viral strains (BZLF1 +) develop more lymphomas than animals infected with replication-defective strains (BZLF1-). ${ }^{14}$ Intratumoral replication can be demonstrated by nuclear expression of the lytic genes in tumor cells in tissue sections. Here we showed for the first time intratumoral replication in primary samples of human post-transplant lymphoma cases. We analyzed the expression of two main genes involved in the initiation of the lytic EBV phase: BZLF1 and BMRF1. Lytic gene products are expressed in three consecutive stages: immediate-early, early, and late. Immediate-early lytic gene products act as transactivators, enhancing the expression of later lytic genes. Early products have a wide array of functions, including replication, metabolism, and blockade of antigen processing, while late products tend to code for structural proteins such as viral capsid antigens and gene products used for immune evasion. Immediateearly BZLF1/ZEBRA and early BMRF1/EADE31 lytic genes are expressed in $60 \%$ of the EBV-associated lymphoma cases in our series. Interestingly, EBV replication seems to occur mostly in a small fraction of the atypical neoplastic cells, although it is difficult to exclude replication in non-neoplastic 
intratumoral cells. This phenomenon is also observed in mice, where although the number of lytically infected cells is low, it is important for the development of lymphoma. The low number of viable lytically infected cells is probably related to the fact that lytic EBV infection may become cytocidal in some cells and may sensitize host cells to NK-cell mediated killing. ${ }^{30-32}$ In spite of the origin of viral particles, either from neoplastic or non-neoplastic cells, the presence of viral particles generates a microenvironment that may promote tumor growth as proposed in other EBV-related disorders. The expression of some lytic genes, such as, BZLF1/ZEBRA induces the secretion of IL10 by B cells promoting B cell survival of both neoplastic and non-neoplastic populations. Moreover, host-infected cells may undergo lysis and allow horizontal spread of EBV from cell to cell increasing the pool of latently infected B cells with active oncogenic viral genes. ${ }^{14}$ Viral replication in tumor cell may be more relevant to tumor biology. In this sense, two lytic genes BHRF1 and BALF1 are viral Bcl-2 homologs that may promote tumor survival. ${ }^{33,34}$

Plasma cell differentiation initiates viral replication of EBV. XBP1 is a transcription factor that positively regulates the expression of the immediate-early gene BZLF1. ${ }^{15,35}$ XBP1 is involved in normal plasma cell differentiation and is expressed in tumors with plasma cell differentiation. ${ }^{17}$ In addition, important B-cell transcription factors repressing plasma cell differentiation have been shown to repress also EBV replication. ${ }^{36,37}$ Curiously most of post-transplant lymphoproliferative disorders exhibit plasma cell differentiation suggesting a connection between these two events in transplant recipients. It is of interest that, as in other aggressive lymphomas, $\mathrm{XBP} 1$ activation is related to aggressive disease. ${ }^{17}$

Latency is the state of persistent EBV viral infection without active viral production. In contrast to lytic replication, there is a limited expression of EBNAs and LMP gene products during latency. ${ }^{11}$ Latency III program, in which all of the latency gene products are expressed, is often detected during acute infectious mononucleosis or in certain immunocompromised individuals. ${ }^{11,38,39}$ This latency program, also known as growth program, while highly characteristic of immunosuppressed individuals, is only observed in $46 \%$ of our EBV-positive cases. This may be explained in part by the tendency to moderate the immunosuppressant regimens in these patients ${ }^{40}$ and to the repression of EBNAs during plasma cell differentiation of latency III infected B cells. ${ }^{5,16,41}$

Latency programs can be disrupted by a variety of cellular activators, resulting in the expression of lytic proteins capable to switch from latency to lytic cycle. Activation of lytic replication or reactivation from latency is the key to the transmission of EBVinfected B cells that are induced to activate their growth program and differentiate into memory B cells via the germinal center reaction. Infected memory B cells are then released into the peripheral blood resulting in detectable levels of virus in the serum. Thus, some authors have used serum PCR to evaluate EBV replication. ${ }^{3,42}$ In our series, a low correlation is observed between PCR in blood and replication analysis in involved organs, similarly to what is observed in other virus that replicates in tissues. ${ }^{43,44}$ In the latent stage, EBV DNA exists as a closed circular episome, replicates once, and only once during $S$ phase, and is equally distributed into daughter cells. ${ }^{45}$ In contrast to lytic replication, episomal replication during the latent phase occurs via host DNA polymerase, therefore insensitive to the standard antiviral therapies that targets only viral DNA polymerase. Thus, the assessment of replicative stage of EBV should be performed before deciding any antiviral therapeutic approach in patients with post-transplant lymphomas. ${ }^{46-48}$

The use of antiviral as prophylactic treatment to prevent post-transplant lymphoma development has been proved to be effective in pediatric cases. ${ }^{19}$ However, in adults, the results are controversial, probably because most of the adults are already infected at the time of transplant and there is not a standardized protocol to study donor and recipient EBV status before transplant. ${ }^{20,49,50}$

The gold standard for post-transplant lymphoproliferative disorder treatment is reduction of immunosuppression with encouraging results in early lesions and some polymorphic cases, whereas it is more controversial in monomorphic ones. It is important to enhance that reducing immunosuppression for treating these subset of lymphomas early after hematopoietic stem cell transplantation is usually not useful. These deeply immunosuppressed patients need more time to recover the immune system and also to eradicate malignant cells, although reducing immunosuppression alone have been occasionally successful in the management of patients following hematopoietic stem cell transplantation.

Current treatment guidelines recommend reduction of immunosuppression at diagnosis and some authors suggest sequential treatment with rituximab and CHOP chemotherapy regimen (ciclofosfamide, doxorubicin, vincristine, and prednisone) in nonresponding patients as first-line treatment when reduction of immunosuppression is not effective. ${ }^{4}$ Nevertheless, the strength of reduction of immunosuppression is variable and tends to be more severe in patients requiring immunochemotherapy. ${ }^{4,9}$ Intriguingly, rituximab and steroids, which are included in the standard treatment regimen of these patients, are known to be potent inductors of EBV replication in vitro. ${ }^{46}$ Moreover, chemotherapy is also shown to reactivate lytic infection rendering tumor cells sensitive to antiviral agents. ${ }^{51}$ EBVspecific cytotoxic T-cell therapy has been proven to be useful for the management of EBV post-transplant lymphoma cases even in rituximab-resistant ones, but unfortunately is not widely available. ${ }^{52}$ 
The proteasome inhibitor bortezomib, that interferes with XBP1 activation in plasma cell tumors also induces lytic virus replication in EBV-infected cells and is currently being evaluated in clinic trials of gamma-herpes virus-associated malignancies including post-transplant lymphomas. ${ }^{53-55}$

In our patients, the simultaneous expression of a latency III pattern associated with intratumoral EBV replication seems to detect a subset of heavily immunosuppressed group of patients with lower rates of rejections or graft vs host disease and higher rates of cytomegalovirus reactivations. These patients have significantly lower overall survival rates and shorter time to develop lymphomas. Although it is possible that this poor outcome was due basically to the particular immunodeficiency of those patients, our data suggest that EBV intratumoral replication has an important role in the aggressive behavior of the tumor. Moreover, the combination of important reduction of immunosuppression with specific targeting of viral replication (antiviral drugs) might eliminate the lytically infected tumor cells and prevent the spreading of EBV and its oncogenic genes to uninfected cells.

\section{Acknowledgments}

AM is supported by Fondo de Investigación Sanitaria and ERDF One way to Europe PI11/00907 and by Instituto de Salud Carlos III. AM, GR, CS, and DC are funded by 'Red Temática de Investigación Cooperativa de Cáncer' (RTICC) RD12/0036/0004. DM is supported by Instituto de Salud Carlos III, "Contratos de Formación en Investigación Río Hortega" CM12/00054. AL-G is supported by SAF 08/SAF 2008-03630 and Instituto de Salud Carlos III, 'Red Temática de Investigación Cooperativa de Cáncer’ (RTICC) RD12/0036/0023. EC is supported by Red Temática de Investigación Cooperativa en Cáncer (RTICC) RD12/0036/0036 and SAF12/38432.

\section{Disclosure/conflict of interest}

The authors declare no conflict of interest.

\section{References}

1 Swerdlow SH, Webber SA, Chadburn A, et al. Post-transplant lymphoproliferative disorders, In: Swerdlow SH, Campo E, Harris NL, et al. (eds). WHO Classification of Tumors of Hematopoietic and Lymphoid Tissues, 4th edn. IARC Press: Lyon, France; 2008, pp 465-469.

2 Dierickx D, Tousseyn T, Sagaert X, et al. Single-center analysis of biopsy-confirmed posttransplant lymphoproliferative disorder: incidence, clinicopathological characteristics and prognostic factors. Leuk Lymphoma. 2013;54:2433-2440.

3 Kroll J, Li S, Levi M, et al. Lytic and latent EBV gene expression in transplant recipients with and without post-transplant lymphoproliferative disorder. J Clin Virol. 2011;52:231-235.

4 Trappe R, Oertel S, Leblond V, et al. Sequential treatment with rituximab followed by CHOP chemotherapy in adult B-cell post-transplant lymphoproliferative disorder (PTLD): the prospective international multicentre phase 2 PTLD-1 trial. Lancet Oncol. 2012;13:196-206.

5 Rasul AE, Nagy N, Sohlberg E, et al. Simultaneous detection of the two main proliferation driving EBV encoded proteins, EBNA-2 and LMP-1 in single B cells. J Immunol Methods. 2012;385:60-70.

6 Leblond V, Davi F, Charlotte F, et al. Posttransplant lymphoproliferative disorders not associated with Epstein-Barr virus: a distinct entity? J Clin Oncol. 1998;16:2052-2059.

7 Ferry JA, Jacobson JO, Conti D, et al. Lymphoproliferative disorders and hematologic malignancies following organ transplantation. Mod Pathol. 1989;2:583-592.

8 Dolcetti R. B lymphocytes and Epstein-Barr virus: the lesson of post-transplant lymphoproliferative disorders. Autoimmun Rev. 2007;7:96-101.

9 Evens AM, David KA, Helenowski I, et al. Multicenter analysis of 80 solid organ transplantation recipients with post-transplantation lymphoproliferative disease: outcomes and prognostic factors in the modern era. J Clin Oncol. 2010;28:1038-1046.

10 Evens AM, Choquet S, Kroll-Desrosiers AR, et al. Primary CNS Posttransplant Lymphoproliferative Disease (PTLD): An International Report of 84 Cases in the Modern Era. Am J Transplant. 2013;13:1512-1522.

11 Siok-Bian N, Lee V, Das K, et al. The relevance of molecular diagnostics in the practice of surgical pathology. Expert Opin Med Diagn 2008;2:1401-1414.

12 Straus SE, Cohen JI, Tosato G, et al. NIH conference. Epstein-Barr virus infections: biology, pathogenesis, and management. Ann Intern Med 1993;118:45-58.

13 Harris NL, Ferry JA, Swerdlow SH. Posttransplant lymphoproliferative disorders: summary of Society for Hematopathology Workshop. Semin Diagn Pathol. 1997;14:8-14.

14 Ma SD, Hegde S, Young KH, et al. A new model of Epstein-Barr virus infection reveals an important role for early lytic viral protein expression in the development of lymphomas. J Virol. 2011;85:165-177.

15 Bhende PM, Dickerson SJ, Sun X, et al. X-box-binding protein 1 activates lytic Epstein-Barr virus gene expression in combination with protein kinase D. J Virol. 2007;81:7363-7370.

16 Taylor GM, Raghuwanshi SK, Rowe DT, et al. Endoplasmic reticulum stress causes EBV lytic replication. Blood 2011;118:5528-5539.

17 Balague O, Mozos A, Martinez D, et al. Activation of the endoplasmic reticulum stress-associated transcription factor $\mathrm{x}$ box-binding protein-1 occurs in a subset of normal germinal-center B cells and in aggressive B-cell lymphomas with prognostic implications. Am J Pathol. 2009;174:2337-2346.

18 Oertel SH, Anagnostopoulos I, Hummel MW, et al. Identification of early antigen BZLF1/ZEBRA protein of Epstein-Barr virus can predict the effectiveness of antiviral treatment in patients with post-transplant lymphoproliferative disease. Br J Haematol. 2002;118: 1120-1123.

19 Hocker B, Bohm S, Fickenscher H, et al. (Val-) Ganciclovir prophylaxis reduces Epstein-Barr virus primary infection in pediatric renal transplantation. Transpl Int. 2012;25:723-731. 
20 Funch DP, Walker AM, Schneider G, et al. Ganciclovir and acyclovir reduce the risk of post-transplant lymphoproliferative disorder in renal transplant recipients. Am J Transplant. 2005;5:2894-2900.

21 Garcia-Herrera A, Song JY, Chuang SS, et al. Nonhepatosplenic gammadelta T-cell lymphomas represent a spectrum of aggressive cytotoxic T-cell lymphomas with a mainly extranodal presentation. Am J Surg Pathol. 2011;35:1214-1225.

22 Valera A, Balague O, Colomo L, et al. IG/MYC rearrangements are the main cytogenetic alteration in plasmablastic lymphomas. Am J Surg Pathol. 2010; 34:1686-1694.

23 van Dongen JJ, Langerak AW, Bruggemann M, et al. Design and standardization of PCR primers and protocols for detection of clonal immunoglobulin and T-cell receptor gene recombinations in suspect lymphoproliferations: report of the BIOMED-2 Concerted Action BMH4-CT98-3936. Leukemia 2003;17: 2257-2317.

24 Cheson BD, Pfistner B, Juweid ME, et al. Revised response criteria for malignant lymphoma. J Clin Oncol. 2007;25:579-586.

25 Caillard S, Lelong C, Pessione F, et al. Post-transplant lymphoproliferative disorders occurring after renal transplantation in adults: report of 230 cases from the French Registry. Am J Transplant. 2006;6: 2735-2742.

26 Webber SA. Post-transplant lymphoproliferative disorders: a preventable complication of solid organ transplantation? Pediatr Transplant. 1999;3:95-99.

27 Chinnock R, Webber SA, Dipchand AI, et al. A 16-year multi-institutional study of the role of age and EBV status on PTLD incidence among pediatric heart transplant recipients. Am J Transplant. 2012;12: 3061-3068.

28 Young LS. Epstein-Barr-virus infection and persistence: a B-cell marriage in sickness and in health. Lancet 1999;354:1141-1142.

29 Hong GK, Gulley ML, Feng WH, et al. Epstein-Barr virus lytic infection contributes to lymphoproliferative disease in a SCID mouse model. J Virol. 2005;79: 13993-14003.

30 Blazar B, Patarroyo M, Klein E, et al. Increased sensitivity of human lymphoid lines to natural killer cells after induction of the Epstein-Barr viral cycle by superinfection or sodium butyrate. J Exp Med. 1980; 151:614-627.

31 Sairenji T, Katsuki T, Hinuma Y. Cell-killing by Epstein-Barr virus: analysis by colony inhibition procedure. Int J Cancer. 1976;17:389-395.

32 Pappworth IY, Wang EC, Rowe M. The switch from latent to productive infection in Epstein-Barr virusinfected B cells is associated with sensitization to NK cell killing. J Virol. 2007;81:474-482.

33 Altmann M, Hammerschmidt W. Epstein-Barr virus provides a new paradigm: a requirement for the immediate inhibition of apoptosis. PLoS Biol. 2005;3:e404.

34 Marshall WL, Yim C, Gustafson E, et al. Epstein-Barr virus encodes a novel homolog of the bcl-2 oncogene that inhibits apoptosis and associates with Bax and Bak. J Virol. 1999;73:5181-5185.

35 McDonald C, Karstegl CE, Kellam P, et al. Regulation of the Epstein-Barr virus Zp promoter in B lymphocytes during reactivation from latency. J Gen Virol. 2010;91: $622-629$.
36 Raver RM, Panfil AR, Hagemeier SR, et al. The B-Cell specific transcription factor and master regulator, Pax5, promotes EBV latency by negatively regulating the viral immediate early protein, BZLF1. J Virol. 2013;87:8053-8063.

37 Robinson AR, Kwek SS, Kenney SC. The B-cell specific transcription factor, Oct-2, promotes EpsteinBarr virus latency by inhibiting the viral immediateearly protein, BZLF1. PLoS Pathog. 2012;8:e1002516.

38 Roschewski M, Wilson WH. EBV-associated lymphomas in adults. Best Pract Res Clin Haematol. 2012; 25:75-89.

39 Young LS, Rickinson AB. Epstein-Barr virus: 40 years on. Nat Rev Cancer. 2004;4:757-768.

40 Srinivas TR, Meier-Kriesche HU. Minimizing immunosuppression, an alternative approach to reducing side effects: objectives and interim result. Clin J Am Soc Nephrol. 2008;3(Suppl 2):S101-S116.

41 Nagy N, Adori M, Rasul A, et al. Soluble factors produced by activated $\mathrm{CD} 4+\mathrm{T}$ cells modulate EBV latency. Proc Natl Acad Sci USA. 2012;109: 1512-1517.

42 Vajro P, Lucariello S, Migliaro F, et al. Predictive value of Epstein-Barr virus genome copy number and BZLF1 expression in blood lymphocytes of transplant recipients at risk for lymphoproliferative disease. J Infect Dis. 2000;181:2050-2054.

43 Mozos A, Garrido M, Carreras J, et al. Redistribution of FOXP3-positive regulatory $\mathrm{T}$ cells from lymphoid tissues to peripheral blood in HIV-infected patients. J Acquir Immune Defic Syndr. 2007;46:529-537.

44 Gotoh K, Ito Y, Maruo S, et al. Replication of EpsteinBarr virus primary infection in human tonsil tissue explants. PLoS One 2011;6:e25490.

45 Tsurumi T, Fujita M, Kudoh A. Latent and lytic Epstein-Barr virus replication strategies. Rev Med Virol. 2005;15:3-15.

46 Daibata M, Bandobashi K, Kuroda M, et al. Induction of lytic Epstein-Barr virus (EBV) infection by synergistic action of rituximab and dexamethasone renders EBV-positive lymphoma cells more susceptible to ganciclovir cytotoxicity in vitro and in vivo. J Virol. 2005;79:5875-5879.

47 Meng Q, Hagemeier SR, Fingeroth JD, et al. The Epstein-Barr virus (EBV)-encoded protein kinase, EBV-PK, but not the thymidine kinase (EBVTK), is required for ganciclovir and acyclovir inhibition of lytic viral production. J Virol. 2010;84: 4534-4542.

48 Odumade OA, Hogquist KA, Balfour HH Jr. Progress and problems in understanding and managing primary Epstein-Barr virus infections. Clin Microbiol Rev. 2011;24:193-209.

49 Aris RM, Maia DM, Neuringer IP, et al. Post-transplantation lymphoproliferative disorder in the Epstein-Barr virus-naive lung transplant recipient. Am J Respir Crit Care Med. 1996;154:1712-1717.

50 Kuo PC, Dafoe DC, Alfrey EJ, et al. Posttransplant lymphoproliferative disorders and Epstein-Barr virus prophylaxis. Transplantation 1995;59:135-138.

51 Feng WH, Israel B, Raab-Traub N, et al. Chemotherapy induces lytic EBV replication and confers ganciclovir susceptibility to EBV-positive epithelial cell tumors. Cancer Res. 2002;62:1920-1926.

52 Doubrovina E, Oflaz-Sozmen B, Prockop SE, et al. Adoptive immunotherapy with unselected or EBVspecific T cells for biopsy-proven EBV + lymphomas 
after allogeneic hematopoietic cell transplantation. Blood 2012;119:2644-2656.

53 Mozos A, Roue G, Lopez-Guillermo A, et al. The expression of the endoplasmic reticulum stress sensor BiP/GRP78 predicts response to chemotherapy and determines the efficacy of proteasome inhibitors in diffuse large b-cell lymphoma. Am J Pathol. 2011;179: 2601-2610.
54 Ling SC, Lau EK, Al-Shabeeb A, et al. Response of myeloma to the proteasome inhibitor bortezomib is correlated with the unfolded protein response regulator XBP-1. Haematologica 2012;97:64-72.

55 Reid EG. Bortezomib-induced Epstein-Barr virus and Kaposi sarcoma herpes virus lytic gene expression: oncolytic strategies. Curr Opin Oncol. 2011;23: 482-487. 